\title{
Architecture of Belonging - A Social Identity-based Design Theory of Community Identification in Multiplayer Video Games
}

\author{
Bastian Kordyaka \\ Chair of Information Systems \\ University of Siegen, Germany \\ Bastian.Kordyaka@uni-siegen.de
}

Marius Mueller

Chair of Information Systems

University of Siegen, Germany

Marius.Mueller@uni-siegen.de

\author{
Samuli Laato \\ Department of Teacher Education \\ University of Turku, Finland \\ Samuli.Laato@utu.fi
}

Bjoern Niehaves

Chair of Information Systems

University of Siegen, Germany

Bjoern.Niehaves@uni-siegen.de

\begin{abstract}
Recently several studies have worked towards a better understanding of reasons to play multiplayer online games (MOGs). Despite multiple approaches used, understanding of the topic remains incomplete due to its complexity. This study constructs an explanatory design theory of community identification as a predictor of engagement in MOGs. To that end, a structured mixed-method study was conducted. First, a quantitative survey $(N=236)$ was used to illustrate the explanatory power of community identification in the specific context of our study. Second, a workshop $(N=10)$ was held identifying similarity and mutual influence as the most meaningful design elements of community identification. On this basis, and building off the design science paradigm, an explanatory design theory to foster community identification in MOGs is derived. The model features the elements of the design factors similarity (high vs. low) and interactive richness (rich vs. poor) that can be tested in future (experimental) research.
\end{abstract}

\section{Introduction}

Multiplayer online games (MOGs), and video games more generally, have grown in popularity to the point that they can be considered one of the most popular, profitable, and innovative forms of entertainment [2]. Because of their popularity, complexity and multi-purpose nature, video games have been a major vein of research in Information Systems (IS) and Human Computer Interaction (HCI) research $[3,6,16,26,57]$ during the past decades. Video games as a contemporary phenomenon can be considered meaningful due to their societal and economic relevance resulting from their increasing popularity and dissemination. Accordingly, they are a form of entertainment [8], but they can also be harnessed for other purposes, as done with, for example, serious games and gamification [1,7]. Current extrapolations suggest that half of the population in Western countries appears to play video games [38], and the video game industry was estimated to be worth $\$ 137$ billion in 2018 [39]. Due to their story of success, video games are a particularly appropriate context to derive insights holding the potential to enrich different neighboring domains (e.g., other online communities). Thus, more research on video games is needed.

Multiple approaches have been used to comprehend the appeal of video games and to identify reasons why players engage with them. Broadly speaking, corresponding studies can be divided into three broad categories: Attitudes and preferences of players [ e.g., 3, 11], demographic factors [ e.g., 7, 10], and gratifications mediated by technology [e.g., 8, 13]. Looking into the heavily researched first category, it can be ascertained that multidimensional approaches of motivation as predictors for video game engagement have been a focal point of scientific endeavors in previous IS and HCI research [e.g., 14, 16], whereby other approaches have gained less attention narrowing the corridor of holistic explanations substantially.

One such approach is yet to be fully explored in the context of video games is the Social Identity Approach (SIA) [51], which is built around the construct of identification with a community (i.e., the psychological feeling of belonging to a certain group) and already explained relevant outcome variables in neighboring domains (e.g., marketing, psychology). The SIA underlines the influence of group based identification 
(with a community) of an individual in a given context as an important influence for subsequent behavior [19, 52]. Occasionally, previous IS and HCI research already showed that community identification is a relevant construct to explain meaningful outcomes (e.g., purchases of virtual goods) in the context of video games [e.g., 10, 13, 16]. However, what is still missing is structured knowledge regarding opportunities to influence community identification on level of technology design. We think that the SIA a suitable approach in the context of our study because it already showed its potential to explain relevant outcomes in the context of digital communities [35] and recent work within the domain of video games [30, 34]. Additionally, the application of the SIA allows us to refer to previous research that identified different antecedent variables of identification in a theory driven manner [19].

Despite the existing empirical knowledge regarding the meaningfulness of community identification as a theoretical construct $[35,43,44]$, it is still unclear how to influence it on a concrete level of technology design. This is surprising because derived insights would allow to the use the social dimension of video games in a more holistic manner and, therefore, increase player engagement and revenue. Corresponding knowledge would be especially meaningful in the highly competitive and fast changing markets of MOGs to maintain or reach competitive advantages and better understand the interaction between technology and players. Accordingly, we consult the design science paradigm providing structured tools to derive valid knowledge regarding the design of technology $[5,20$, $32,41]$.

Taken together, this paper aims to explore how community identification can be influenced by technology design. For this, we make use of a mixedmethod approach comprising of two steps. First, we use a quantitative survey to illustrate the explanatory potential of the SIA in the specific context of our study, in relation to a widely used approach of motivation as an empirical baseline. Accordingly, we compare the explanatory power of community identification and motivation as predictors of engagement. The results of this analysis reveals an estimate of the importance of community identification as a measure of long-term engagement in MOGs, Second, we consult insights related to previous research on the SIA [19] and conduct a focus group workshop with stakeholders from different domains of video game design to identify meaningful design elements that remain unexploited to date related to community identification following a structured design extraction approach [37].

Based on the derived information, we propose an explanatory design theory of identification with the community based on assumptions from the design science paradigm that can be quantitatively tested in future research [4]. As a context for our study, we refer to the popular game genre MOG (comprising different sub-genres and games like Fortnite, League of Legends). Summarizing, our paper is guided by the subsequent two research questions:

RQ1: To what extend does community identification explain player engagement?

RQ2: What design elements (potentially) foster identification with the community?

Having information regarding the meaningfulness of community identification in MOGs and a design theory of community identification in place enables both the industry and academia to better understand video game players. Accordingly, the acquired knowledge can be used to ensure different business-related benefits (e.g., increase revenue by ensuring loyalty) as well as improving player behavior (e.g., increase the engagement of users). Additionally, a design theory of community identification can enrich neighboring disciplines such as gamification, which has a growing presence in sectors such as business, health and learning as well. In order to understand the idea of our study, related works on MOGs, community identification, and corresponding consequences need to be introduced.

\section{Related Work}

\subsection{Design Science Paradigm}

As the overarching theoretical framework for our study, we draw upon research on design science to gain knowledge about the design of the class of IT artifacts MOGs [20]. Theories in design science can be differentiated into design practice theories and explanatory design theories $[12,32]$. Whereas design practice theories are concerned with the design process and therefore answer the question of how an IT artefact should be constructed [41], explanatory design theories strive to explain why a design artefact should be constructed with specific components [5, 12, 32]. More precisely, explanatory design theories consist of at least one hypothesis that contains a component (design item) that can be systematically variated as an independent variable and a desirable or undesirable outcome variable (dependent variable) using the terminology of structural equation modelling [40]. In this terminology, the design items as well as the items of measured constructs represent latent variables, which can only be measured with a certain degree of measurement error. The relationships between the latent variables (hypotheses) 
represent the inner model, and the operationalization of the latent variables (design items and, in most cases, questionnaire items) represent the outer model.

Design science theories are usually mid-range theories limited to a certain design context, constructed by refining kernel theories that are valid in a broader application field [31]. Whereas kernel theories are highly abstract and lack the connection to specific design items, mid-range theories in the form of explanatory design theories have a medium level of abstraction and make specific propositions about the design-related latent variables and their operationalization's. Thus, explanatory design theories need to be informed by kernel theories, and the general constructs of kernel theories are translated to the designrelevant constructs [32]. This is a major issue in explanatory design theorizing, as it provides a potential source of error because of the distance between the latent design variable and its corresponding design items [40]. Consequently, kernel theories and their mapping to respective design items play a major role in the construction of explanatory design theories.

Since the main goal of our study is a better understanding of how to influence community identification in MOGs on a level of game design, we want to derive an explanatory design theory of community identification. For this, we explore the explanatory power of community identification for relevant outcomes, identify points of references on a level of game design and corresponding kernel theories to derive a testable design theory using the terminology of structural equation modelling. Hereby, we seek to identify design items as independent variables as predictors of our dependent variable community identification.

\subsection{Community Identification}

To theoretically capture community identification, we refer to the social identity approach (SIA), which is a widespread theory from social psychology explaining intergroup and individual behavior $[19,51]$. The SIA is built around the concept of identity that can be understood as a collection of beliefs relating to defining characteristics about oneself. The theory assumes that the self of an individual is constructed in a given situation using personal (e.g., the player as an individual) and social aspects (e.g., the video game player as a group member) of identity [14]. Individuals strive for a positive self, therefore they use social comparisons with the aim of maintaining or enhancing a positive self and attaining positive distinctiveness to other individuals and groups [51]. Within the SIA, the visible part of the self to others can vary between situations. For example, the role of an individual in a romantic relationship and at work can be fundamentally different. Identification with a group has only scarcely been used to explain the appeal of video games. However, a few authors [25, 29, 45] use the theory to explain how social influences affect video game players with promising results. We assume that the SIA is an appropriate approach for the purposes of our study because it has the potential to describe identity as an entity constructed in a given situation. Accordingly, the level of community identification differs based on the available stimuli.

Previous research already indicated different desired consequences of community identification [e.g., $10,13,16]$. For the purpose of our paper, we want to explore the predictive power of community identification for video game engagement. Whereby, engagement can be defined as a behavior characterized by energy, involvement, and efficacy that happens rather unconsciously as a pervasive long-lasting state [27]. Previous research has already found indicators that engagement is closely related to profitability of organizations because it holds the potential to enhance customer satisfaction, loyalty, trust, and brand evaluations [18]. Accordingly, MOG designers should to maximize players' engagement by building an environment that helps to foster engagement to significantly increase their market presence. How to foster engagement in video games remains an open question and knowledge regarding concrete design elements to increase players engagement (mediated through identification with the community) is rather unidentified.

\subsection{Context of the Study}

As a context for our study, we refer to Multiplayer Online Games (MOGs) as the technological artifact of interest, which consist of different sub-genres of multiplayer video games (e.g., Multiplayer Online Battle Arena, battle royal) that are played in real time over the internet. Up to the present day, MOGS enjoy growing economic success and societal meaningfulness. League of Legends as an example, had more than 115 million active players world-wide in 2019 and made \$ 1.4 billion of revenue in 2018 [49]. Looking at related re-search in a simplistic manner, two broad categories of topics can be differentiated. First, negative consequences like violence [9] and physical correlates [36] have been investigated. Second, studies tested positive aspects like motivational drivers to play [22, $54]$, explanations for revenue made $[15,17,29]$, or the acquisition of competencies in video games that are relevant in the real word as well [24, 42]. Since we want to better understand the influence of identification with the community as a predictor of MOG play, which we 
frame as a proxy to different desired outcomes (e.g., satisfaction, loyalty), we anchor our study within the second category.

\section{The Explanatory Power of Community Identification}

In order to study the relationship between community identification and play, we subsequently show the used quantitative methodology and the corresponding findings.

\subsection{Methodology}

Design and data analysis.

We used a cross-sectional survey to collect self-reports of players with an online questionnaire and analyzed the resulting data with co-variance-based statistics.

Data sampling and participant characteristics.

To derive a meaningful sample of respondents, we used the crowd-work platform Clickworker. As prerequisites to participate in our study, we required participants to have substantial experiences playing in at least one MOG. To make sure this prerequisite was fulfilled, we asked three different questions of MOG knowledge in the beginning of our survey (e.g., "Please select the games that fit the definition of a MOG") and excluded participants who failed one of them. The inquiry took place in January 2019 and lasted three days. All participants received a reward of $1.10 €$ as a compensation for their participation. After cleaning the raw data of our sample from incomplete and bogus cases, the final sample of our study consisted of 236 participants. The age of the participants was 33 years on average $(\mathrm{M}=33.38, \mathrm{SD}=10.72)$ and ranged from 17 to 68 years. The vast majority of our sample consisted of males (150 males, 86 females). Most participants came from Germany (116) or North-America (34) and stated that the highest academic degree they currently held was a high school diploma (50) or bachelor's degree (54). Additionally, participants had been playing video games around 14 years $(\mathrm{M}=13.98, \mathrm{SD}=8.99)$. In addition, close to one third of participants specified that they predominantly play action games (e.g., Fortnite), followed by one fifth who play strategy games (e.g., League of Legends, DOTA 2), and one fifth who play sports games (e.g., FIFA).

To check the representative nature of our sample, we compared the demographic characteristics of our sample to general characteristics of video game players in the United States using different sources of research $[48,50]$. Taken together and based on the comparison of both samples (see Table 1), we assumed our sample to be representative for the wider population of video game players.

\begin{tabular}{l|c|c} 
Characteristic & General sample & Our sample \\
\hline Age & 35 & 33 \\
Gender & $60 \%(\mathrm{~m})$ & $63 \%(\mathrm{~m})$ \\
Years of play & 13 & 14
\end{tabular}

Table 1. Representative nature of our sample

\section{Measurements.}

To measure the constructs relevant for our study, we used empirically validated scales from literature adapted to the context of our study wherever necessary. The majority of scales used a seven-point Likert scale (1 = "strongly disagree", 7 = "strongly agree").

\section{Dependent variable.}

We measured video game engagement by asking participants for their frequency of play, the average time spent playing video games, and the amount of games they played every week during the year 2019 regarding the chosen MOG. We aggregated all three variables to a single variable $(\mathrm{M}=3.75, \mathrm{SD}=.97, \alpha=.71)$.

\section{Independent variables.}

First, to have a point of reference we used a scale with twelve items consisting of the three motivational dimensions immersion (e.g. "...to feel immersed in the world"; $\mathrm{M}=5.09$, SD = 1.16, $\alpha=.79$ ), achievement (e.g., "...to compete with other players"; $\mathrm{M}=5.01$, SD $=1.18, \alpha=.75$ ), and social motivation (e.g., "...to chat with other players"; $\mathrm{M}=4.31, \mathrm{SD}=1.51, \alpha=.86$ ) with four items each [2]. Second, we measured identification with the community with a validated scale consisting of four adapted items ("I identify with the community of the video game"; $\mathrm{M}=3.64, \mathrm{SD}=.87, \alpha=.83$ ) from previous literature [32].

\section{Control variables.}

To have the chance to control for unwanted effects, we surveyed game type, platform, and experience of play. Additionally, we used a widespread scale of the Big Five to control for personality traits (BFI-2-S) to control for potential confounds resulting from the personality of participants [34]. The scale comprises the dimensions openness $(\mathrm{M}=3.41, \mathrm{SD}=.60, \alpha=.63)$, conscientiousness $(\mathrm{M}=3.61, \mathrm{SD}=.58, \alpha=.62)$, extraversion $(\mathrm{M}=3.20, \mathrm{SD}=.70, \alpha=.71)$, agreeableness $(\mathrm{M}=3.61, \mathrm{SD}=.59, \alpha=.67$, and neuroticism $(\mathrm{M}=2.70, \mathrm{SD}=.72, \alpha=.79)$. 


\subsection{Results}

To test the explanatory power of identification with the community regarding video game engagement, we proceeded in two subsequent steps. First, we ran some preceding analyses inserting demographic (age, gender, education, country) and control variables (game type, platform, experience of play, personality traits) as predictors of the dependent variable video game engagement. The regression equation illustrated a significant result $(\mathrm{F}(12,223=3.73, \mathrm{p}<.001)$ and explained $12 \%$ of the variance. After using the false discovery rate to avoid the multiple comparison problem the regression coefficients of country $(\beta=-.19, p<.05)$ and agreeableness $(\beta=.18, \mathrm{p}<.05)$ showed significant effects (all others $<.05$ ). Second, to answer our first research question, we compared identification with the community and motivation as explanations for video game engagement. To test motivation, we inserted immersion motivation, achievement motivation, and social motivation as predictors of video game engagement, while controlling the influences of the identified confounds country and agreeableness. The regression equation showed a significant result $(\mathrm{F}(5,230$ $=7.18, \mathrm{p}<.001)$ and explained $12 \%$ of video game engagement. After using the false discovery rate, country $(\beta=.24, \mathrm{p}<.01)$ agreeableness $(\beta=.05, \mathrm{p}<$ $.01)$, and the social motivation $(\beta=.22, \mathrm{p}<.05)$ showed a significant effect explaining video game engagement (all others $\mathrm{p}>.05$ ). To test the explanatory power of identification, we inserted identification as a predictor of video game engagement, while controlling for the identified confounds. The regression equation showed a significant result $(\mathrm{F}(3,232=29.98, \mathrm{p}<.001)$ and explained $27 \%$. After using the false discovery rate, the regression coefficients of country $(\beta=-.21, \mathrm{p}<.01)$ and identification $(\beta=.46, p<.001)$ showed significant effects explaining video game engagement (all others $p$ $\geq .05$ ). In spite of the smaller number of predictors and the resulting less degrees of freedom our results indicate that identification in with the community in fact explains bigger shares of the variance of video game engagement compared to motivation ( $27 \%$ vs. $12 \%)$.

\begin{tabular}{l|c|c|c|c} 
& $\mathrm{df}$ & $\mathrm{F}$ & $\mathrm{p}$ & $\mathrm{R}_{\text {adj }}^{2}$ \\
\hline Motivation & 5 & 7.18 & $<.001$ & $12 \%$ \\
Identification & 3 & 29.98 & $<.001$ & $27 \%$
\end{tabular}

Table 2. Comparison of approaches

\section{Towards a Design Theory for Community Identification}

In order to derive a design theory to increase the identification with the community in MOGs, we subsequently illustrate the methodology and the corresponding findings.

\subsection{Methodology}

Procedure.

To derive design elements creating the opportunity for game developers to increase the identification with the community, we refer to focus group research [47]. Accordingly, we adapted a structured design identification procedure from previous research [37] comprising four steps: (1) ideation (e.g., unveiling an initial set of design requirements, introducing the technological artefact, and the usage scenarios); (2) selection of design elements (e.g., frequencies of covered nominations); (3) practicability of design elements (e.g., a group discussion); (4) theory construction (e.g., deriving a testable design theory after the workshop). For the purposes of the fourth step, we make use of assumptions from design science research. Accordingly, we derive an explanatory design theory (opposed to design practice theories) that explains why certain components are constructed into an artifact to influence community identification $[4,11,13,41,56]$. Specifically, we use a validated framework that allows researchers to quantitatively test design theories using tools related to structural equation modelling [40]. Here, the distinction between the outer (i.e., relationships between the latent variables and their measurements) and the inner (structural) model (i.e., justificatory knowledge consisting of kernel theories and their relationships) can be used to derive a testable theory.

Data sampling and participant characteristics. We involved different groups of stakeholders who are familiar with the design of video games to participate in our workshop. Accordingly, we derived a sample of ten participants from the networks of our institution. As a process of selection, we send an email about the workshop to members of our networks briefly explaining the content of the workshop and asking people to apply to it. Afterwards, we selected candidates based on their experience and professional diversity. The focus group session lasted around two hours and the age of the participants was 32 years on average $(M=32$. 20, SD = 3.47). All participants had substantial experiences playing at least one MOG for more than ten years. The focus group consisted of stakeholders from the domains of technology development (i.e., two participants), game design (i.e., four participants), and 
social and computer sciences (i.e., four participants). Eight of the participants were males and most of them came from Germany (8).

\subsection{Results}

Step 1: The initial ideation phase of the workshop involved all of the ten participants, a moderator, and a recording clerk. After welcoming the participants, the procedure of the workshop was introduced. Afterwards, the relevant case (i.e., MOGs), requirements of the design elements (e.g., expanding opportunities for players to identify with the community on a level of game design), and the four relevant usage scenarios general client (i.e., the initial screen after starting the client), match-making (i.e., the screen both teams can see during their champion selection beforehand a game), loading-screen (i.e., the screen both teams see while the game is loading; see Fig. 1), in-game (i.e., the screen every player sees during the game) were introduced by the moderator in order to establish a common understanding of the purpose of the event.

Step 2: Before the start of the selection phase, the procedure was introduced and demographic data from all participants was collected. Afterwards, we made use of a theoretical scaffold of social connectivity that proved its usefulness in neighboring disciplines to increase the identification with the community [19]. Accordingly, we requested the workshop participants to rate a list of five elements (i.e., similarity, trust, ability to communicate, mutual influence, ability to cooperate) on a scale from 1 "not useful at all" to 10 "very useful" to potentially increase community identification in MOGs that already showed its usefulness in neighboring disciplines. Participants stated that the most meaningful design elements were similarity $(\mathrm{M}=8.40, \mathrm{SD}=1.52)$, mutual influence $(\mathrm{M}=7.6, \mathrm{SD}=2.07)$, and trust $(\mathrm{M}=$ 7.00, $\mathrm{SD}=.71)$.

Step 3: Within the next phase, the practicability of the design elements of community identification were discussed to identify potential obstacles. Simultaneously, the moderator loosely categorized and continuously rearranged the mentioned aspects, visualizing them on a whiteboard. Except of the design element of trust (participants stated that they believed that trust is rather a dependent consequence of design and community identification) no sincere obstacles were found. Afterwards, participants were discharged and thanked for their efforts.

Step 4: After the workshop, we build on the information derived in the previous steps to propose a testable design theory to foster community identification in MOGs. Accordingly, we used the identified design elements 'similarity' and 'mutual influence' as well as the assumption that identification can be manipulated in a given situation from the SIA [19]. Accordingly, it seems justified to visually manipulate the perception of players using different conditions.

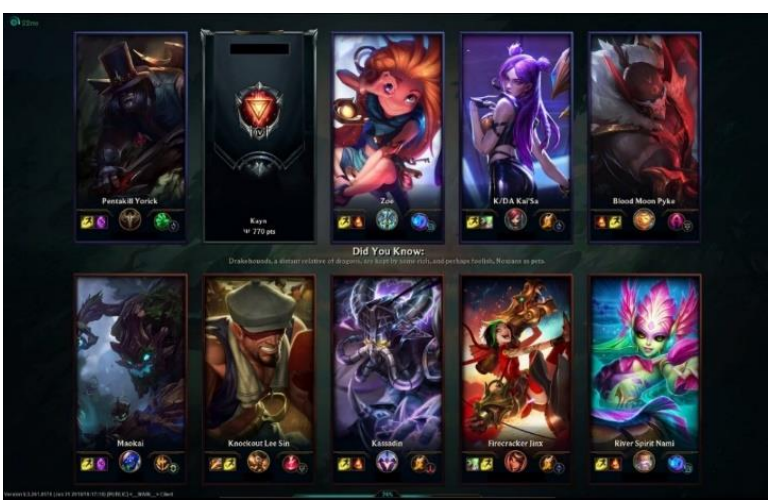

Fig. 1. Screenshot of the usage scenario "loading-screen".

First, we propose the contrast model as our kernel theory for the factor similarity (high vs. low) towards other players [23], which considers the relative influence of common and distinctive features on perceived similarity as a function of the context [53]. Since the majority of MOGs currently uses a rather undifferentiated approach during all usage scenarios, it can be used as a low similar condition. For the high similar condition, players can be matched to clusters based on demographic information (e.g., country, age) and make this visually recognizable, which is an additional information indicating the perception of similarity towards other players and subsequently increase community identification.

Second, we propose interaction richness (rich vs. poor) as a proxy of the identified design element 'mutual influence'. Accordingly, we refer to the model of interaction richness as our second kernel theory, which assumes the depth of interaction between actors to have beneficial consequences [21]. Despite first attempts to use interactive elements during the loading screen, the design element can be further enriched by using information regarding previous behavior of players. Accordingly, we propose the current status quo as the low interaction condition. For the high interaction condition, we propose to visually indicate previous ratings of the social behavior of a specific player (e.g., using the framework of the chosen champion and varying the color). To measure the dependent variable 'community identification', we refer to the quantitative part of this study and a scale consisting of four items [26]. Conclusively, we propose the subsequent explanatory design theory that can be tested in future research (Fig. 2).

To test the proposition of our explanatory design theory of community identification, the technique of 
structural equation modelling can be used. For this the two factors of the design model similarity (high vs. low) and interaction richness (high vs. low) can be operationalized in the form of different mockups of the four usage scenarios (in a randomized order) and community identification can be measured with an established measurement. As a method we propose the quantitative technique of a 2 (similarity: low vs. high) $\mathrm{x}$ 2 (interaction richness: low vs. high) factorial design to test the explanatory design theory of community identification.

\section{Discussion}

Based on the results of our approach, we were able to answer our two research questions. First, as an answer to our first research question (To what extend does community identification explain player engagement?), we illustrated that community identification is a particular meaningful predictor of video game engagement exceeding the explanatory power of motivation. This insight is especially meaningful since community identification as a point of reference to enhance desired outcomes has not been fully used. Second, as an answer to our second research question (What design elements (potentially) foster identification with the community?) we identified design elements which have the potential to positively influence community identification in MOGs. Third, we proposed a structured (explanatory) design theory of community identification, which can provide value for game designers.

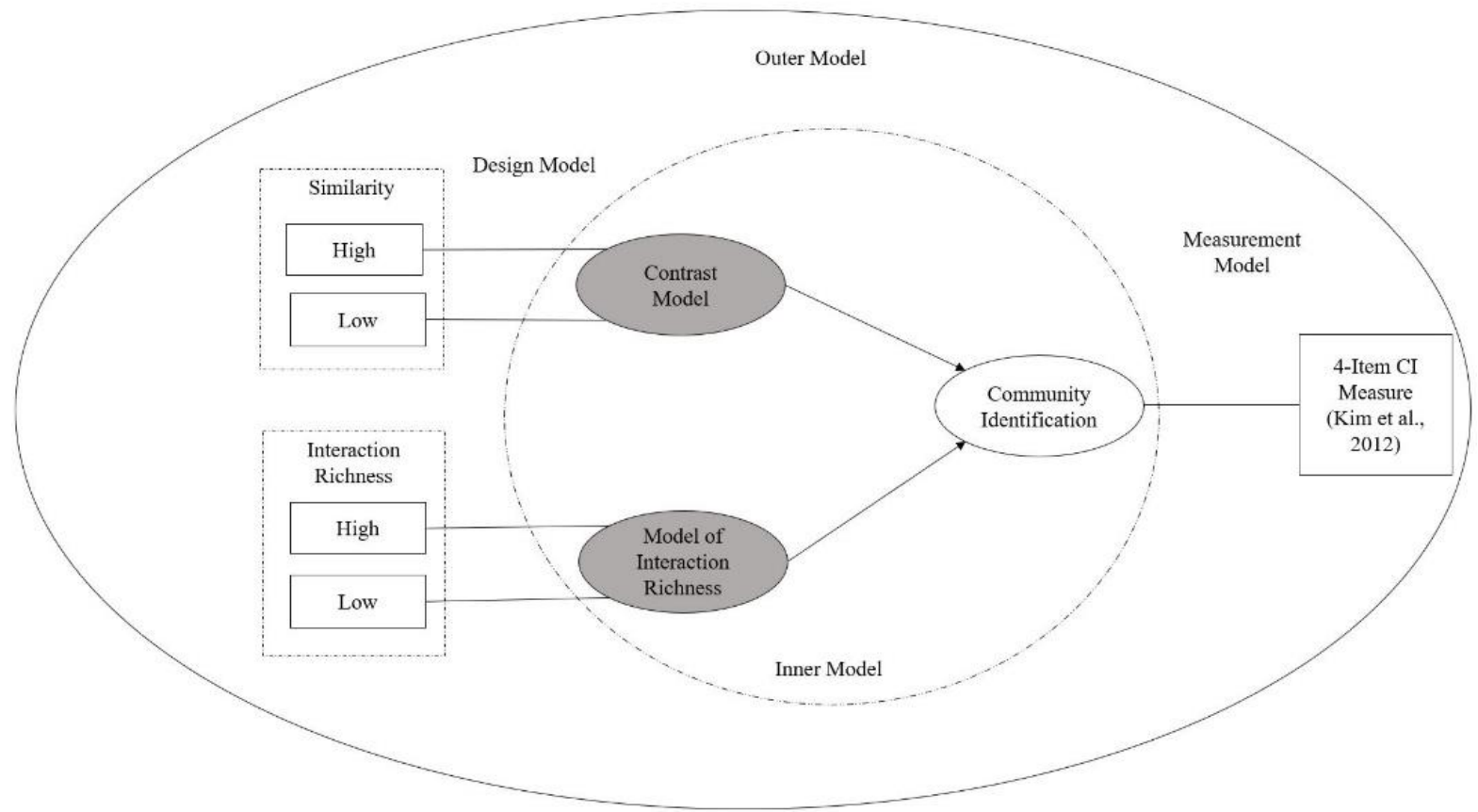

Fig. 2. Design theory of community identification in MOGs

\subsection{Theoretical implications}

The results of our paper comprise several contributions which are interesting on a theoretical level. First, we found empirical indicators that the consideration of community identification and the application of the SIA in the context of MOGs is promising. Accordingly, we validated existing research explaining video games [20-22] and increased the external validity of the SIA $[17,18]$. We understand this finding as a call for more diverse approaches extending current approaches explaining video game engagement. Accordingly, our insights allow for a better understanding of one contemporary and especially meaningful form of artefact use. Second, the derived design theory of community identification as a predictor of engagement seems promising because it is built around a structured framework that can be empirically tested. Even though the original design elements were taken from previous research, we were able to show the usefulness and practicability of design elements to increase community identification in the context of MOGs. We understand this finding in a way that it seems beneficial for researchers to look into the origins of theories and identify interdependences deductively. Nonetheless, they could be complemented by more 
creative tools (e.g., design thinking). Third, we contribute to the understanding of polarization as an emergent phenomena of MOGs with static teams [33]. Through identifying the design principles that scaffold community identification, we support intervention studies that aim to curb social polarization among MOG players.

\subsection{Practical Implications}

Looking at our findings from a practical perspective, we present some aspects that seem to be particularly relevant. First, game designers can use the knowledge derived in our study to create games ensuring community identification with higher levels of player engagement. Based upon our finding that community identification exceeds the explanatory power of motivation to predict engagement, game designers can contemplate this insight and design additional opportunities to increase the identification with the community. This could be achieved by transferring functionalities from neighboring technologies like social media platforms (e.g., bulletin boards, self-selected groups, or autograph books) to the context of MOGs and give players the chance to receive a more holistic impression of others. However, we encourage game designers to make use of the insights derived in our study. As an example, this could be achieved with the application of market segmentation techniques based on players attitudes and preferences to ensure the perception of higher levels of similarity to others. Second, games looking to increase player retention and engagement can use design science approaches to gain more holistic insights into the game design. For example, other design elements than similarity and interaction richness could be used and tested for their effect on community identification.

In the light of our findings, scaffolding player identity is highly important for long-term engagement on MOGs. However, this finding also applies to engagement with other products and services. In the larger picture major game companies have moved away from the business model of selling a new game every year or two to their players, and instead, MOGs are being updated and upgraded constantly to keep players engaged for prolonged periods of time. This paradigm shift has been made possible and profitable by the increasing use of micro transactions as a revenue stream. Due to the significant role of (social) identity in player engagement, we predict business strategies considering player identity more in the future.

\section{Limitations and Outlook}

Like every empirical study our study includes limitations. Here we name the most relevant of them and illustrate potential ways how future research can deal with them. First, as operationalizations for our two predictor variables of engagement (i.e., motivation and community identification) we used rather economic scales. This was intended since the main goal of our study was to determine the explanatory power of community identification on a general level. Nonetheless, we encourage future research to use more detailed instruments to measure predictors of engagement to look for effects on a more granular level and test the stability of our findings. Second, although we controlled for effects of personality and demographic data additional con-founds might have played a role explaining engagement which we could not control for. We recommend to consult additional approaches (Flow Theory, Cognitive Load Theory) which already proved its usefulness explaining video game engagement. Third, the derivation of the design theory presented in this paper exhibits certain limitations as well. Accordingly, the influencing variables of community engagement came from previous research and have not been used in the context of game design. We encourage future studies to further explore the identified individual design elements, for example, by comparing two similar games. Future works investigating MOGs social features could also benefit from the findings of this study as such, as they can be used to explain at least partially why players keep playing the games. As our empirical studies were crosssectional, a final important venue for future work is to investigate and confirm the role of identity in MOGs over time.

\section{Conclusion}

This study explored community identification as a predictor for engagement in MOGs. Based on the results of a conducted survey $(\mathrm{N}=236)$, we showed that identification with the community explained engagement more accurately than a widely used motivational approach (i.e., consisting of immersion motivation, achievement motivation, and social motivation). Thus, this study showed that it is feasible to use community identification as a predictor of engagement. To illustrate how the potential of community identification can be used by game designers a continuation study was carried out involving a workshop $(\mathrm{N}=10)$. The main goal of the workshop was to evaluate design elements which scaffold the forming of community identification. Based on the results, a 
testable design theory was derived built around the contrast model and the model of interaction richness.

\section{References}

[1] Abt, C.C., Serious Games, University press of America, Maryland (Lanham), 1987.

[2] Argenio, A., "Statistically, Video Games Are Now the Most Popular and Profitable Form of Entertainment", Gamecrate, 2018 . https://www.gamecrate.com/statistically-video-gamesare-now-most-popular-and-profitable-formentertainment $/ 20087$

[3] Bartle, R., "Hearts, Clubs, Diamonds, Spades: Players Who Suit MUDs", Journal of MUD research 1(1), 1996, pp. 19.

[4] Baskerville, R., "Individual information systems as a research arena", European Journal of Information Systems 20(3), 2011, pp. 251-254.

[5] Baskerville, R., and J. Pries-Heje, "Explanatory Design Theory", Business \& Information Systems Engineering 2(5), 2010, pp. 271-282.

[6] Chen, V.H.-H., H.B.-L. Duh, and C.W. Ng, "Players Who Play to Make Others Cry: The Influence of Anonymity and Immersion", Proceedings of the International Conference on Advances in Computer Entertainment Technology, ACM (2009), pp. 341-344.

[7] Dale, S., "Gamification: Making Work Fun, or Making Fun of Work?", Business Information Review 31(2), 2014, pp. 82-90.

[8] De Schutter, B., and J.A. Brown, "Digital Games as a Source of Enjoyment in Later Life", Games and Culture 11(1-2), 2016, pp. 28-52.

[9] Gentile, D., "Pathological Video-Game Use Among Youth Ages 8 to 18: A National Study", Psychological Science 20(5), 2009, pp. 594-602.

[10] Greenberg, B.S., J. Sherry, K. Lachlan, K. Lucas, and A. Holmstrom, "Orientations to Video Games Among Gender and Age Groups", Simulation \& Gaming 41(2), 2010, pp. 238-259.

[11] Gregor, S., "The Nature of Theory in Information Systems", MIS Quarterly 30(3), 2006, pp. 611-642.

[12] Gregor, S., "Building Theory in the Sciences of the Artificial", Proceedings of the 4th International Conference on Design Science Research in Information Systems and Technology, (2009), pp. 1-10.

[13] Gregor, S., and D. Jones, "The Anatomy of a Design Theory", Journal of the Association for Information Systems 8(5), 2007, pp. 312-335.

[14] Guan, M., and J. So, "Influence of Social Identity on SelfEfficacy Beliefs Through Perceived Social Support: A Social Identity Theory Perspective", Communication Studies 67(5), 2016, pp. 588-604.

[15] Guo, Y., and S. Barnes, "Why People Buy Virtual Items in Virtual Worlds with Real Money", ACM Sigmis Database 38(4), 2007, pp. 69-76.

[16] Hamari, J., and L. Keronen, "Why Do People Play Games? A Meta-Analysis", International Journal of Information Management 37(3), 2017, pp. 125-141.

[17] Hamari, J., and V. Lehdonvirta, "Game Design as Marketing: How Game Mechanics Create Demand for
Virtual Goods", Journal of Business Science and Applied Management 5(1), 2010, pp. 15-29.

[18] Harter, J.K., F.L. Schmidt, and T.L. Hayes, "BusinessUnit-Level Relationship Between Employee Satisfaction, Employee Engagement, and Business Outcomes: A Meta-Analysis.”, Journal of Applied Psychology 87(2), 2002, pp. 268-279.

[19] Haslam, S.A., P.J. Oakes, K.J. Reynolds, and J.C. Turner, "Social Identity Salience and the Emergence of Stereotype Consensus", Personality and Social Psychology Bulletin 25(7), 1999, pp. 809-818.

[20] Hevner, A.R., S.T. March, J. Park, and S. Ram, "Design Science in Information Systems Research", MIS Quarterly 28(1), 2004, pp. 75-105.

[21] Jahng, J., H. Jain, and K. Ramamurthy, "Effects of Interaction Richness on Consumer Attitudes and Behavioral Intentions in E-Commerce: Some Experimental Results", European Journal of Information Systems 16(3), 2007, pp. 254-269.

[22] Jeng, S.-P., and C.-I. Teng, "Personality and Motivations for Playing Online Games", Social Behavior and Personality: An International Journal 36(8), 2008, pp. 1053-1060.

[23] Johnson, M.D., "Consumer Similarity Judgments: A Test of the Contrast Model", Psychology and Marketing 3(1), 1986, pp. 47-60.

[24] Keith, M.J., G. Anderson, J. Gaskin, and D.L. Dean, "Team Video Gaming for Team Building: Effects on Team Performance", AIS Transactions on HumanComputer Interaction 10(4), 2018, pp. 205-231.

[25] Kim, H.-W., and H.C. Chan, "Why People Pay for Digital Items? Presentation Desire of Online Identity", Proceedings of PACIS 2007, 2007, pp. 214-226.

[26] Kim, H.-W., H.C. Chan, and A. Kankanhalli, "What Motivates People to Purchase Digital Items on Virtual Community Websites? The Desire for Online SelfPresentation", Information Systems Research 23(4), 2012, pp. 1232-1245.

[27] Kim, Y.H., D.J. Kim, and K. Wachter, "A Study of Mobile User Engagement (MoEN): Engagement Motivations, Perceived Value, Satisfaction, and Continued Engagement Intention", Decision Support Systems 56, 2013, pp. 361-370.

[28] Koivisto, J., and J. Hamari, "Demographic Differences in Perceived Benefits from Gamification", Computers in Human Behavior 35, 2014, pp. 179-188.

[29] Kordyaka, B., and S. Hribersek, "Crafting Identity in League of Legends - Purchases as a Tool to Achieve Desired Impressions", Proceedings of the 52nd Hawaii International Conference on System Sciences (HICSS52), 2019, pp. 1506-1515.

[30] Kordyaka, B., S. Laato, K. Jahn, and S. Hribersek, "Designing Community Identification - A Multi-Method Approach", Proceedings of the European Conference on Information Systems (ECIS 2020), 2020.

[31] Kuechler, B., and V. Vaishnavi, "On Theory Development in Design Science Research: Anatomy of a Research Project", European Journal of Information Systems 17(5), 2008, pp. 489-504.

[32] Kuechler, W., and V. Vaishnavi, "A Framework for Theory Development in Design Science Research: 
Multiple Perspectives", Journal of the Association for Information Systems 13(6), 2012, pp. 395-423.

[33] Laato, S., N. Inaba, and M. Paloheimo, "The Effect of Team Choice in Ingress and Pokémon GO for Players' Social Circles and Attitudes Towards Game Slang", Proceedings of the 53rd Hawaii International Conference on System Sciences 2020, (2020), pp. 2660-2669.

[34] Laato, S., B. Kordyaka, S. Rauti, et al., "Do Primal Instincts Explain Engagement in Location-Based Games? A Hypothesis-Forming Focus Group Study on Territorial Behavior", Proceedings of the 4th International GamiFIN Conference 2020, 2020, pp. 115125.

[35] Ma, M., and R. Agarwal, "Through a Glass Darkly: Information Technology Design, Identity Verification, and Knowledge Contribution in Online Communities", Information systems research 18(1), 2007, pp. 42-67.

[36] Mentzoni, R.A., G.S. Brunborg, H. Molde, et al., "Problematic Video Game Use: Estimated Prevalence and Associations with Mental and Physical Health", Cyberpsychology, Behavior, and Social Networking 14(10), 2011, pp. 591-596.

[37] Mueller, M., O. Heger, B. Kordyaka, H. Kampling, and B. Niehaves, "Beyond Intuition: Towards a Framework for Empirical-Based Design Theory Building in Design Science Research", Advances in Design Science Research, pp. 5715-5724.

[38] Muriel, D., and G. Crawford, Video Games as Culture: Considering the Role and Importance of Video Games in Contemporary Society, Routledge, Abingdon, 2018.

[39] Newzoo, "Newzoo's 2018 Report: Insights Into the \$137.9 Billion Global Games Market”, Newzoo, 2019. https://newzoo.com/insights/articles/newzoos-2018report-insights-into-the-137-9-billion-global-gamesmarket/

[40] Niehaves, B., and K. Ortbach, "The Inner and the Outer Model in Explanatory Design Theory: The Case of Designing Electronic Feedback Systems", European Journal of Information Systems 25, 2016, pp. 303-316.

[41] Peffers, K., T. Tuunanen, M.A. Rothenburger, and S. Chatterjee, "A Design Science Research Methodology for Information Systems Research", Journal of Management Information Systems 24(3), 2008, pp. 4577.

[42] Petter, S., D. Barber, C. S. Barber, and R. A. Berkley, "Using Online Gaming Experience to Expand the Digital Workforce Talent Pool", MIS Quarterly Executive 2018(4), 2018.

[43] Rai, A., "Editors' Comments: Seeing the Forest for the Trees", MIS Quarterly 41(4), 2017, pp. iii-vii.
[44] Ren, Y., F.M. Harper, S. Drenner, et al., "Building Member Attachment in Online Communities: Applying Theories of Group Identity and Interpersonal Bonds", MIS Quarterly 36 (3), 2012, pp. 841-864.

[45] Setterstrom, A.J., and J.M. Pearson, "Social Influence and Willingness to Pay for Massively Multiplayer Online Games: An Empirical Examination of Social Identity Theory", Communications of the Association for Information Systems 44(1), 2019, pp. 34-61.

[46] Sjöblom, M., and J. Hamari, "Why Do People Watch Others Play Video Games? An Empirical Study on the Motivations of Twitch Users", Computers in Human Behavior 75, 2017, pp. 985-996.

[47] Stahl, B.C., M.C. Tremblay, and C.M. LeRouge, "Focus Groups and Critical Social IS Research: How the Choice of Method Can Promote Emancipation of Respondents and Researchers", European Journal of Information Systems 20(4), 2011, pp. 378-394.

[48] Statista, "U.S. Average Age of Video Gamers 2018 Statistic", Statista, 2018. https://www.statista.com/statistics/189582/age-of-usvideo-game-players-since-2010/

[49] Statista, "LoL Global Revenue 2018", Statista, 2019. https://www.statista.com/statistics/806975/lol-revenue/

[50] Statista, "U.S. Video Gamer Gender Statistics 2018", Statista, 2019 https://www.statista.com/statistics/232383/gender-splitof-us-computer-and-video-gamers/

[51] Tajfel, H., and J.C. Turner, "The Social Identity Theory of Intergroup Behavior.", in Jost, J.T: and Sidanius J., Key Readings in Social Psychology. Political Psychology: Key Readings, 2004, pp. 276-293.

[52] Turner, J.C., P.J. Oakes, S.A. Haslam, and C. McGarty, "Self and Collective: Cognition and Social Context", Personality and Social Psychology Bulletin 20(5), 1994, pp. 454-463.

[53] Tversky, A., "Features of Similarity.", Psychological review 84(4), 1977, pp. 327-352.

[54] Vahlo, J., and J. Hamari, "Five-Factor Inventory of Intrinsic Motivations to Gameplay (IMG)", Proceedings of the 52nd Hawaii International Conference on System Sciences, 2019, pp. 2476-2485.

[55] Vahlo, J., J.K. Kaakinen, S.K. Holm, and A. Koponen, "Digital Game Dynamics Preferences and Player Types", Journal of Computer-Mediated Communication 22(2), 2017, pp. 88-103.

[56] Winter, R., "Design Science Research in Europe", European Journal of Information Systems 17(5), 2008, pp. 470-475.

[57] Yee, N., "Motivations for Play in Online Games", CyberPsychology \& behavior 9(6), 2006, pp. 772-775. 